\title{
Fault-valve behaviour and episodic gas flow in overpressured aquifers - evidence from the 2010 Ms5.1 isolated shallow earthquake in Sichuan Basin, China
}

\author{
Xinglin Lei* \\ Geological Survey of Japan, \\ National Institute of Advanced Industrial Science and Technology, \\ AIST Central \#7, Higashi 1-1-1, \\ Tsukuba, Ibaraki, 305-8567, Japan \\ and \\ State Key Laboratory of Earthquake Dynamics, \\ China Earthquake Administration, \\ Institute of Geology, \\ Beijing 100029, China \\ Email: xinglin-lei@aist.go.jp \\ *Corresponding author

\section{Shengli Ma}

State Key Laboratory of Earthquake Dynamics,

China Earthquake Administration,

Institute of Geology,

Beijing 100029, China

Email: masl@ies.ac.cn

\section{Xiaolong Wang}

Chonqing Earthquake Administration,

Chongqing 401147, China

Email:cqdzj_5449@qq.com

\section{Jinrong Su}

Sichuan Earthquake Administration, Chengdu 610041, Sichuan-Province, China

Email:sujr0816@163.com

\begin{abstract}
We investigated the 2010 Ms5.1 Suining earthquake (a temporally and spatially isolated event) centred in Moxi gas field in the tectonically stable central region of Sichuan Basin, China. The focal depth is estimated to be approximately $2.8 \mathrm{~km}$ and thus the earthquake is nucleated in Triassic marine sediment, coincident with the depths of the top boundary of an overpressured gas reservoir. The strike/dip/rake of the estimated source fault is $223 / 48 / 122$, showing a rupture area of a dimension of $\sim 2.4 \mathrm{~km}$ along a blind reverse fault in agree with the geological structures and regional stress regime of this area. Through an integrated analysis, we propose that the associated fault slip of this earthquake was most probably initiated and driven by gas injection from the underlying overpressured reservoir into the shallower gas reservoirs. No aftershocks following the Suining earthquake indicates that the gas injection from the deeper reservoir is somewhat episodic and a fault-valve behaviour.
\end{abstract}

Keywords: overpressured reservoir; fault-valve behaviour; episodic fluid flow; numerical simulation.

Reference to this paper should be made as follows: Lei, X., Ma, S., Wang, X. and Su, J. (2017) 'Fault-valve behaviour and episodic gas flow in overpressured aquifers - evidence from the 2010 Ms5.1 isolated shallow earthquake in Sichuan Basin, China', Progress in Computational Fluid Dynamics, Vol. 17, No. 1, pp.2-12. 
Biographical notes: Xinglin Lei is graduated from China University of Geosciences in 1983. He received his $\mathrm{PhD}$ from Institute of Geology, China Earthquake Administration (CEA) in 1990. $\mathrm{He}$ is a senior researcher of Seismology and Geo-mechanics at Geological Survey of Japan, National Institute of Advanced Industrial Science and Technology in Japan. In recent years, he conducts integrated research using multiple methods (laboratory experiments, field surveys, and numerical simulations) on multi-scales (core- and field-scales, and natural analogue) for studies in areas such as seismology, geological disposal of $\mathrm{CO}_{2}$ and other waste products, shale gas, and enhanced geothermal systems.

Shengli Ma is the General Director of Institute of Geology, CEA. He received his $\mathrm{PhD}$ from Institute of Geology, CEA in 1997. He conducts laboratory and field studies on rock fracturing and fault frictional behaviours.

Xiaolong Wang is working for Chongqing Earthquake Administration. His major fields are seismic monitoring and deep structure inversion using receives function and surface waves.

Jinrong $\mathrm{Su}$ is working for Sichuan Earthquake Administration. Her major fields are seismic monitoring and analysis of regional seismic activity.

\section{Introduction}

Temporally isolated moderate-size (approximately M5) earthquakes, with no aftershocks or an exceptionally low level of aftershock activity, have been observed in a wide range of tectonic environments, including: subducted lithosphere in the low mantle (Boddington et al., 2004; Lundgren and Giardini, 1994), regions of low seismicity (Bowman et al., 1990; Michael-Leiba et al., 1994; Stauder and Pitt, 1970), seismically active zones (Bakun and McEvilly, 1981; Nicholson et al., 1988; Schwartz and Christensen, 1988), areas of remotely triggered seismicity (Lei et al., 2011), and areas of injection induced seismicity (Lei et al., 2008, 2013). Generally, one earthquake always raises the odds that there will be another, the mechanism of isolated moderate-size earthquakes is thus an interesting issue which remains poorly understood.

On 1 October 2010, an earthquake of Ms 5.1 occurred in Moxi gas field located in the central uplift region of Sichuan Basin, China. This earthquake is termed the Suining or Suining-Tongnan earthquake because it was centred in a gas reservoir at the boundary of Suining county of Sichuan and Tongnan county of Chongqing (Figure 1). No aftershocks were identified from the Sichuan Earthquake Administration (SEA) array data above the detection threshold magnitude of approximately 2.5 for this area. Two portable seismic stations were installed by the Chonqing Earthquake Administration (CEA) in about 10 hours after the earthquake. In this region, such stations can detect shallow earthquake of magnitude greater than 0.5 (Lei et al., 2013), but no aftershocks were recorded. The Suining earthquake is significant for four reasons. First, no aftershocks were recorded, indicating it was a temporally isolated earthquake. Second, the hypocenter of this earthquake was located in a natural gas reservoir that is in operation. Third, this earthquake occurred in a seismically stable region, in which no earthquake has been recorded for more than one thousand years. Fourth, it has a very shallow focal depth (Luo et al., 2011), the maximum damage intensity reaches VII (Chinese standard) and many houses were heavily damaged (He et al., 2010).

The Suining earthquake is well recorded instrumentally by the regional seismic network of the SEA and the CEA. This provides an opportunity to obtain a relatively detailed view of the source processes which, when integrated with the well-known deep structure of the gas reservoir, can improve our understanding of shallow isolated earthquakes.

\section{Source parameters}

Inversion using the cut and paste (CAP) method shows that the best focal depth falls into the range of 2-6 km (Zhang et al., 2011). Surface wave modelling and analysis of depth phases recorded at distant stations suggested a depth range of $2 \pm 1.5 \mathrm{~km}$ (Luo et al., 2011). According to the experience of a farmer whose house was located very close to the epicentre, when the earthquake occurred he felt that his bed was raised vertically and then moved horizontally. The farmer's testimony is important evidence that S-waves came very soon after the P-wave first motion, probably in less than a half period of the P-wave, approximately $0.5 \mathrm{~s}$, indicating the focal depth is less than $3 \mathrm{~km}$. At a location approximately $120 \mathrm{~km}$ southwest of the epicentre of the Suining earthquake, there occurred a well-monitored injection-induced swarm, known as the 2009-2010 Zigong sequence (Lei et al., 2013). Most events were located in the Maokou limestone/dolomite formation $\left(\mathrm{P}_{2}\right)$ (Lei et al., 2013). It is a generally recognised that shallower events generate stronger surface waves. Since the deep structures at the two sites are quite similar, a comparison of waveforms focusing on Rayleigh waves is helpful for judging the focal depth of earthquakes in a site without nearby stations. We found that the surface wave pattern of the Ms5.1 Suining earthquake, as shown in Figure 2, was similar to events of focal depth approximately $3 \mathrm{~km}$ from the 2009-2010 Zigong sequence. 
Figure 1 Map view showing location and seismological features of the southwestern Sichuan Basin (see online version for colours)

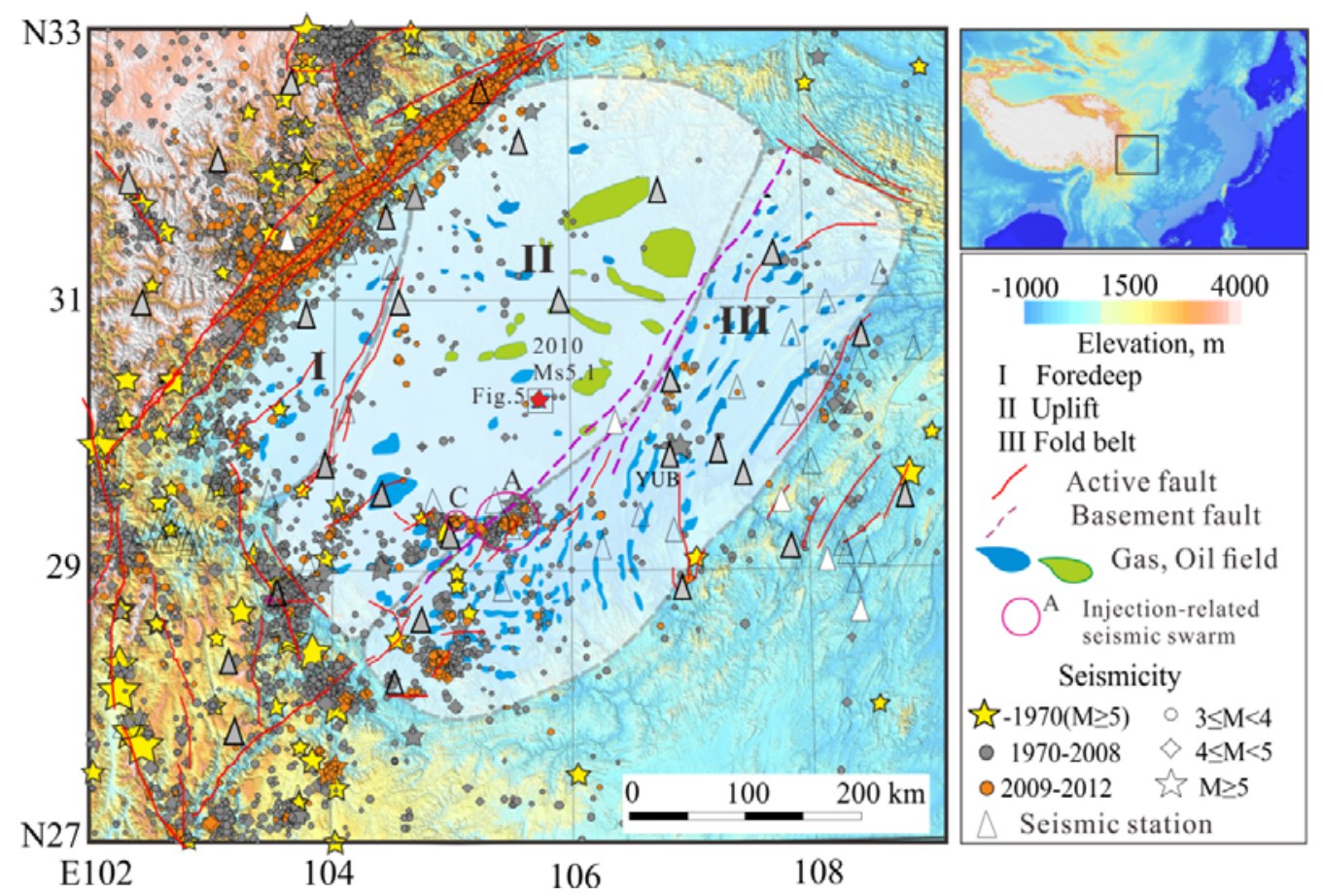

Notes: The isolated Ms5.1 earthquake (red star) is located in the centre of the basin and is a stable region. Seismic clusters in the highlighted area such as that indicated as $\mathrm{A}$ and $\mathrm{C}$ are induced/triggered by fluid injection in gas reservoirs and/or salt mines. The grey triangles indicate the wideband seismic stations used in CAP inversion, while white triangles indicate stations used in Figure 4.

In order to obtain reliable focal depth and source mechanism solutions, we inverse the full moment tensor using the generalise cut and paste method (gCAP) (Zhu and Ben-Zion, 2013) and seismograms recorded by 31 broad-band seismometers (Figure 1). An improved 1D velocity model obtained by receiver function inversion for a nearby site (Wang et al., 2013) was used. The misfit error as function of focal depth indicates the best focal depth was $2.8 \mathrm{~km}$ from the surface. The best solution shows an almost pure double-couple mechanism. The strike/dip/rake angles of two nodal planes of the best solution are 223/48/122 and $360 / 51 / 60$, respectively (Figure 3 ). In addition, we focused on some depth phases including $\mathrm{pP}$ and $\mathrm{sP}$ phases which give a strong constraint on the focal depth. As showed in Figure 4, seismograms recorded at some stations of proper epicentre distance and azimuth show very small amplitude of the P-wave 1 st motion and very clear sP phases. These sP phases give a focal depth range from 2.0 to $2.5 \mathrm{~km}$. With consideration of the deep structures and distribution of damage intensity, we take the result from our gCAP inversion as best fit and suggest that the strike, dip angle, and rake of the source fault are 223, 48, and 122, respectively. Thus, the source fault is a reverse fault with strike-slip component. Such a fault is optimally oriented under the present day stress field in the region. The principal stress directions are in agreement with the regional stress field in the central Sichuan Basin.

After combining all results and information, we suggest $2.8 \mathrm{~km}$ to be the focal depth, which coincides with the top boundary of the overpressured gas reservoir in the lower
Triassic Jialingjiang limestone/dolomite formation. As schematically shown in Figure 4, the seismograms, radiation patterns (polarisation and amplitude) of the suggested mechanism solution, simplified mean velocity structures, identified depth phases (sP), and shallow focal depth are in agreement with each other.

We further applied spectra analysis to estimate the corner frequency, stress drop and rupture radius by assuming a circular rupturing zone on the fault.

The recorded displacement spectral amplitude $A(f)$ is given by the production of the source term $S(f)$, the path term $D(f)$, the geometrical spreading $G(R)$, and the instrument response $I(f)$ :

$$
A(f)=S(f) D(f) G(f) I(f)
$$

where $R$ is the hypocentre distance, $f$ is frequency. Equation (1) works for both $P$ and $\mathrm{S} / \mathrm{Lg}$ waves with different $S(f)$, $D(f)$, and $G(R)\left(\mathrm{m}^{*} \mathrm{~s}\right)$ terms for the respective wave types.

The path term $D(f)$ can be expressed as (Ottemöller and Havskov, 2003)

$$
D(f)=\exp \left[\frac{-\pi T f}{Q_{0} f^{\alpha}}\right] \exp (\pi k f)
$$

where $Q_{0}$ and $\alpha$ are constant defining the frequencydependent attenuation of seismic waves. Based on theoretical model (Aki, 1967), the source term is given by:

$$
S(f)=\frac{M_{o}}{3.32 \pi \rho v^{3}}\left[1+/\left(f / f_{c}\right)^{3}\right]^{-1}
$$


where $f_{c}$ is the corner frequency, $M_{o}$ is the seismic moment. The moment magnitude is defined as a function of seismic moment by (Kanamori, 1977):

$$
\begin{aligned}
M_{w}= & \frac{2}{3} \log M_{o} \\
& -6.07\left(\text { unit of } M_{o} \text { is } \mathrm{N}^{*} \mathrm{~m}\left(10^{7} \text { dyne* }^{*}\right)\right)
\end{aligned}
$$

By assuming a circular rupturing asperity, the stress drop $\Delta \sigma$ is estimated by (Eshelby, 1957):

$$
\Delta \sigma=\frac{7 M_{o}}{16 r^{3}}
$$

Figure 2 Three-component velocity seismograph of the Ms5.1 Suining earthquake and a M3.8 event of well determined focal depth in another site recorded by the wide-band seismometer of YUB station (epicentre distance $\mathrm{R}=136 / 150 \mathrm{~km}$ )

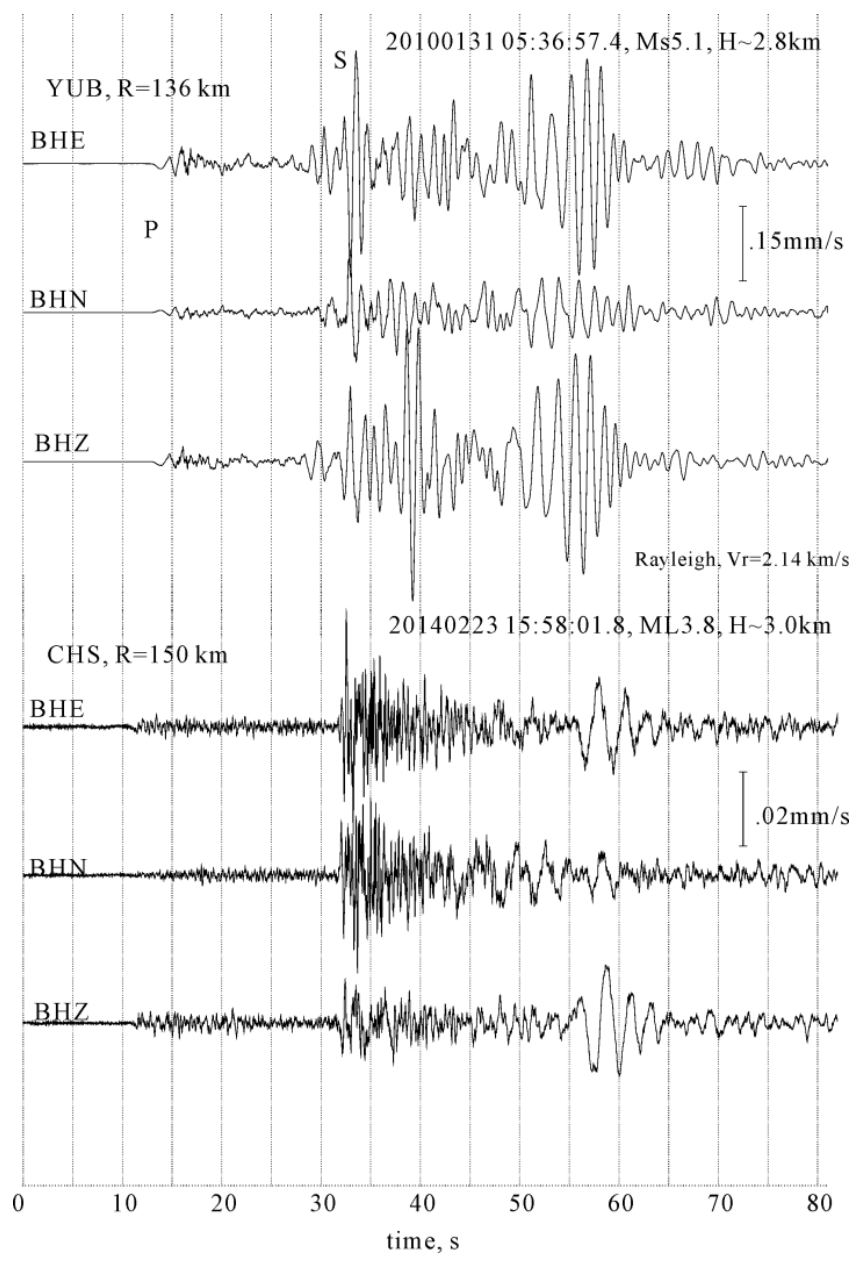

Note: Clear S phases and strong surface waves indicate a shear fracturing mechanism and a very shallow focal depth (see text for detail).
Figure 3 Misfit error as function of focal depth obtained using gCAP inversion (see online version for colours)

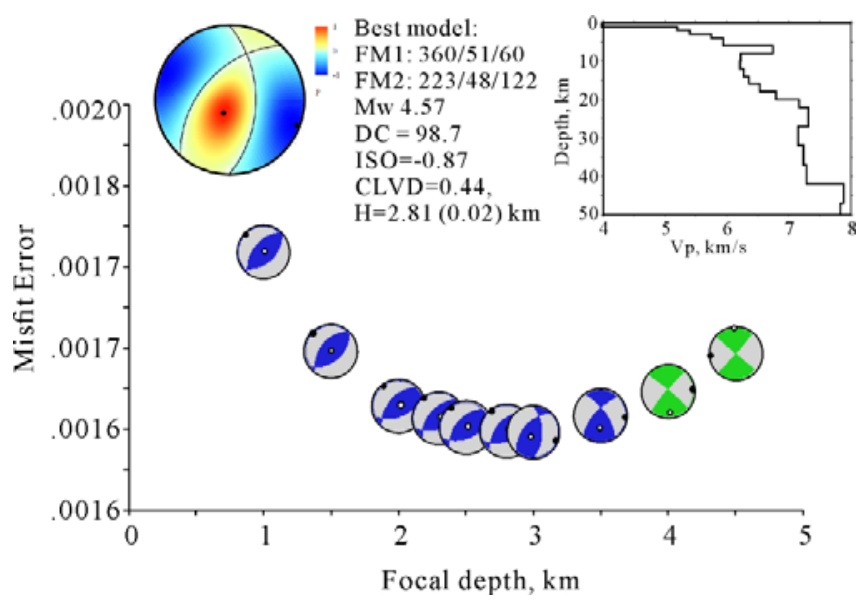

Note: The inner plots show the best model and the regional $1 \mathrm{D}$ velocity profile used in the inversion.

The $P$ wave corner frequency $f_{c}$ and the radio of the asperity $(r)$, can be estimated using following relation (Madariaga, 1976):

$$
\begin{aligned}
& f_{c}=\frac{0.423 V s}{\left(M_{o} / \Delta \sigma\right)^{1 / 3}} \\
& r=\frac{0.21 V s}{f_{c}}(\operatorname{assuming} V r=08 V s)
\end{aligned}
$$

where $V s$ is shear wave velocity.

Both $f_{c}$ and $M_{o}$ can be estimated by minimising the misfit function between the observed and synthetic spectral amplitudes. The following previous studies (Ottemöller and Havskov, 2003), the misfit function $E$ is defined as:

$$
E=\left[\sum_{i}\left|a_{o b s, i}-a_{s y n, i}\right|^{n}\right]^{1 / n}
$$

where $n=1$ or 2 , both produce equally good results. If the catalogue $M w$ is well defined, $f_{c}$ is the only free parameter.

We applied these theories to wideband seismograms of the Suining earthquake. Figure 5 shows and typical example of fitting results with assumed parameters. The estimated moment magnitude is 4.83 , which is in agreement with the value 4.57 estimated by moment tensor inversion. The estimated values of corner frequency, stress drop and rupture radius are approximately $0.8 \mathrm{~Hz}, 4 \mathrm{MPa}$, and $1.2 \mathrm{~km}$, respectively. These values fall into the general ranges of a typical tectonic earthquake of the same magnitude. Thus, the ruptured zone is limited in the depth range from $1.9 \mathrm{~km}$ to $3.7 \mathrm{~km}$. Our results indicate that it is impossible to create surface fractures. 
Figure 4 Seismograms recorded at different epicentre distances along a line perpendicular to the strike of the source fault, and ray paths of the 1st P-wave calculated for the 1D mean velocity model of the Sichuan Basin (see online version for colours)

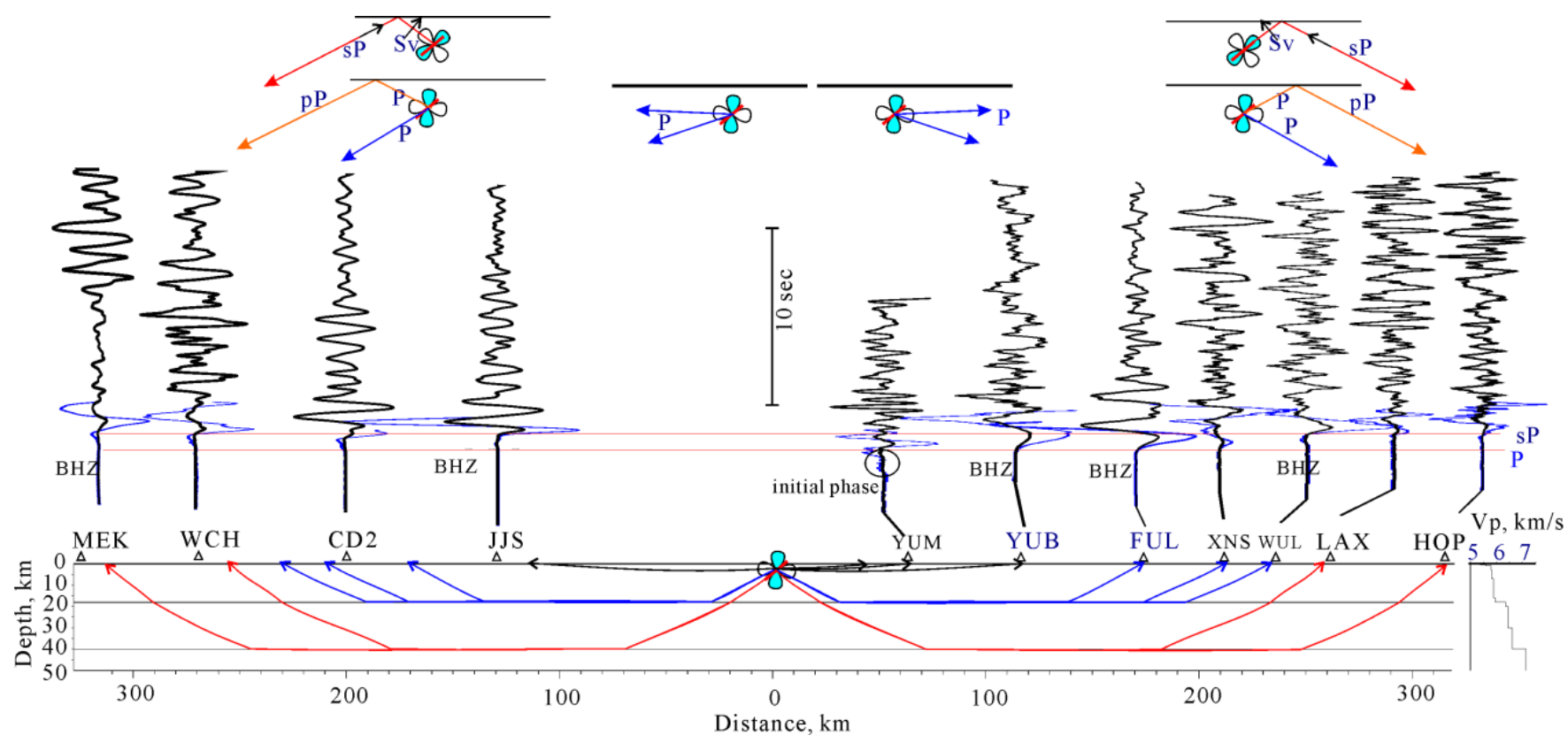

Notes: The source fault and far field P-wave and S-wave radiation patterns from suggested focal mechanism solution are also plotted. Scaled waveforms (blue) are plotted to show the very weak P-wave 1st motion.

Figure 5 Example of amplitude spectrum, assumed parameter, and estimated source parameters of the 2010 Suining Ms5.1 earthquake (see online version for colours)

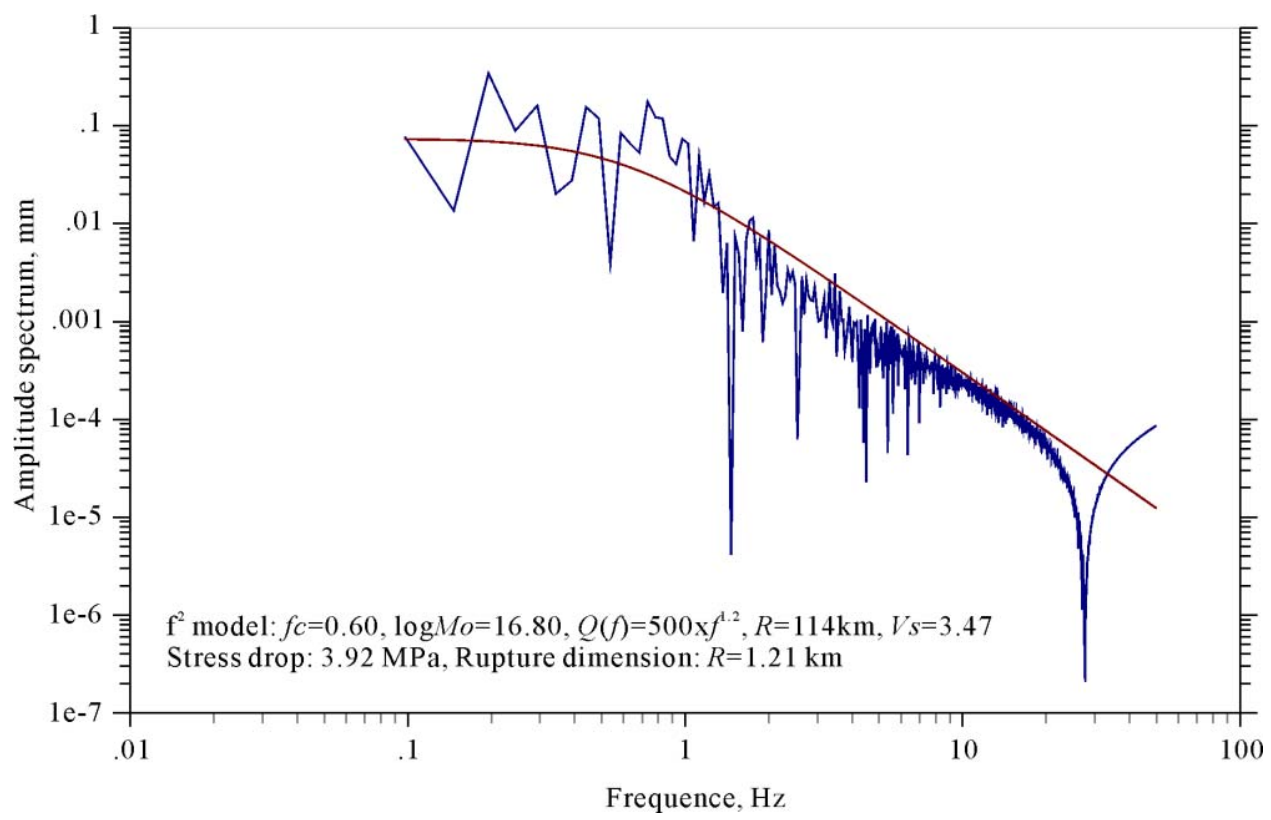


Figure 6 Map view showing key data in Moxi gas field: reservoir boundary, faults, and radon anomaly data (after Jia et al., 2005), and distribution of damage intensity (Chinese standard) caused by the 2010 Ms5.1 earthquake (after He et al., 2010) (see online version for colours)

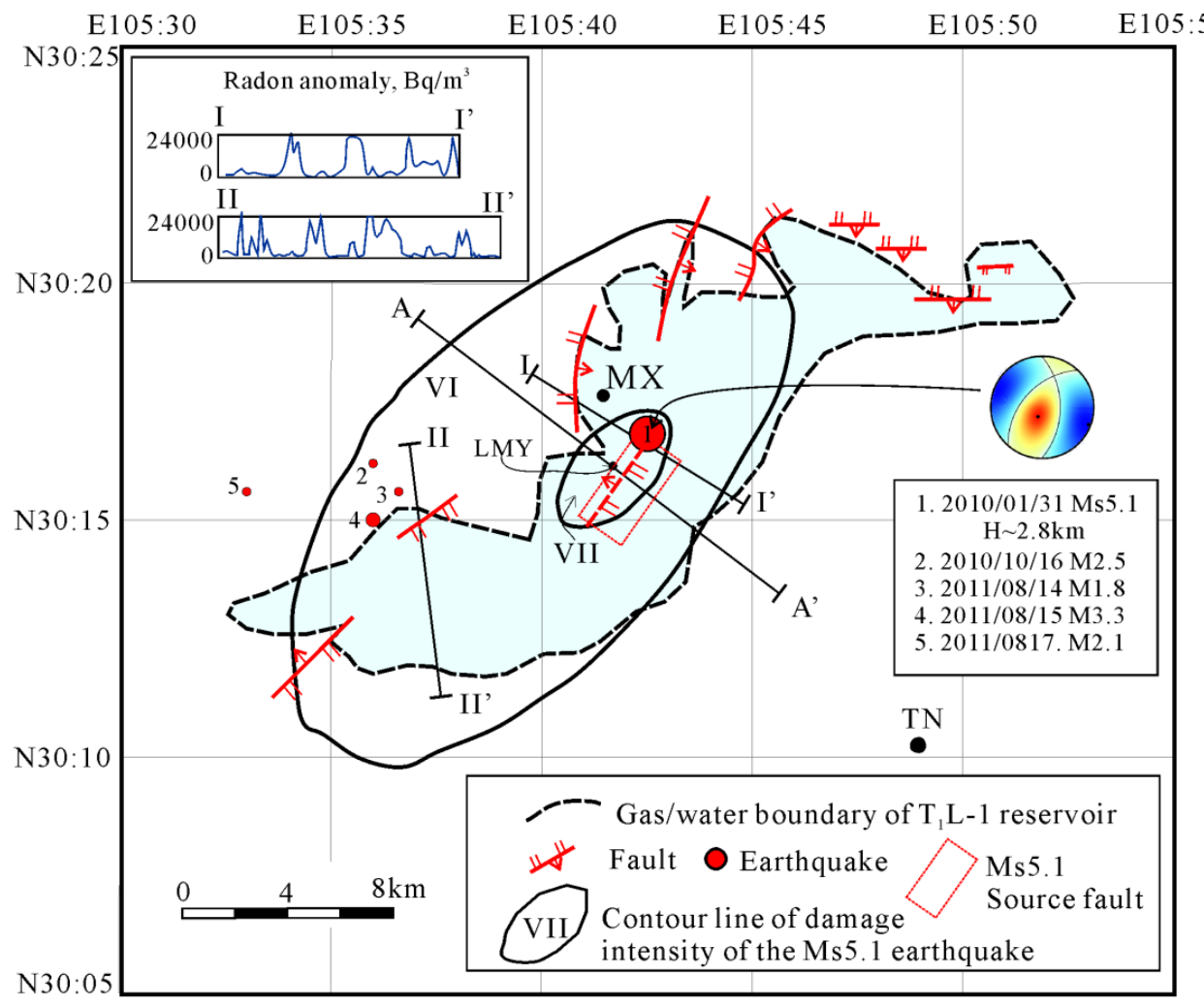

Notes: The faults are traces on the top surface of the Leikou formation which is $\sim 2,500 \mathrm{~m}$ below the grand surface. The radon anomaly is measured along lines at the ground surface. Where MX and TN are Moxi town and Tongnan County, respectively.

\section{Tectonic and petroleum-geologic backgrounds}

The Sichuan Basin in southwestern China is located within the northwest portion of the stable South China block. The basin is characterised by three major units:

1 a northwestern depression on the northwest

2 a northeast trending central uplift

3 a southeastern fold belt on the southeast (Figure 1).

Sediment layers, overlying the Pre-Cambrian crystalline basement, show a gradual thinning from approximately 13 northwest to approximately $7 \mathrm{~km}$ southeast. In the central uplift unit, the upper layer is lightly deformed with flat folds, blind (few exposed) reverse faults, and widely distributed detachments at different depths along evaporative layers. The crystalline basement is characterised by strong metamorphic rock. The Sichuan Basin, with the exception of its boundaries, is relatively stable. However, in the southwest of the basin, there have been a number of seismic swarms, which mirror fluid injections and thus are important (Lei et al., 2008, 2013).

Dolomite/limestone layers, which are capped by gypsum layers, in the Leikoupo formation $\left(\mathrm{T}_{2} \mathrm{l}\right)$ have a porosity in the range of $5.84 \% \sim 12.59 \%$ and permeability between
$0.0073 \sim 37.2 \mathrm{mD}$ (Wang et al., 1998). Gas in the locally developed dolomite layers in Jialingjiang formation $\left(T_{1} j\right)$ shows high pressure with a pressure ratio $\mathrm{R} \sim 2.2$ (Xu et al., 2006). Studies of carbon isotopes, biomarker com pounds, and three-dimensional fluorescence characteristics indicate that the Upper Permian and Middle to Lower Triassic reservoirs in the Moxi structure are predominately dominated by upward migration and accumulation. Gas in the reservoirs below the Leikoupo Formation originates mainly from the upper Permian coals (Dai et al., 1998; Li, 2012; Wang et al., 1998). Both vertical migration through faults and horizontal migration within the dolomite layers have a role in gas accumulation (Dai et al., 1998; Wang et al., 1998).

In the Moxi gas field, the gas-water boundary of most reservoirs coincides with peaks of radon anomaly while known faults show high radon anomaly. Thus, faults, which promote slow upward movement of fluid at low permeability, are leakage paths and control the boundaries of gas pools (Jia et al., 2005). The depth of the gas-water interface in the lowest reservoir in $T_{2} 1$ is $\sim 3,000 \mathrm{~m}$ below the surface and is clearly controlled by some intra-layer faults mapped from boring data and seismic profiles (Bai, 1992) (Figures 6 and 7). 
Figure 7 Simplified geological cross-sections, stratigraphy, and major reservoirs along the profile marked by A-A' in Figure 6 (see online version for colours)

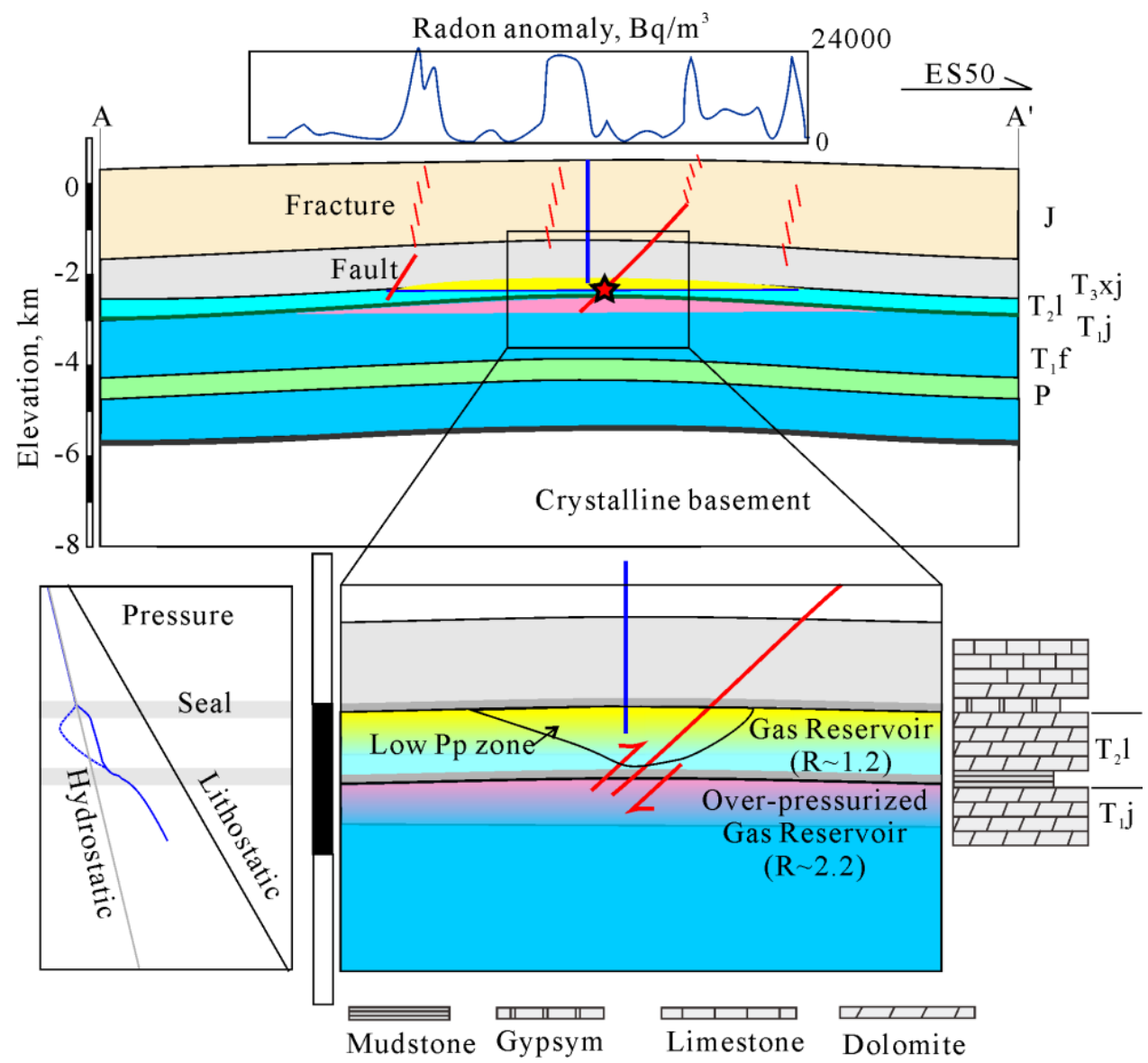

Notes: The top plot shows radon anomaly. Peaks of radon anomaly are an indication of gas/water boundary, fault, and possible leakage channels.

\section{Role of gas production - a numerical simulation}

It is known that pore-elastic stressing from long-term extraction may impart substantial stresses on the surroundings and trigger earthquakes such as the well documented cases in the Lacq gas field in France (Segall, 1992; Segall et al., 1994). In our cases, gas extraction from the upper reservoir in the Leikoupo formation $\left(T_{2} l\right)$ has been operated and depleted for several years, and the reservoir pressure had been significantly lowered. It is important to investigate the effect of gas extraction from the upper reservoir. We thus carried out fault stability analysis based on a simplified numerical simulation to estimate changes of Coulomb failure stress and slip tendency on the source fault of the Suining earthquake.

\subsection{Fault stability analysis - Coulomb failure stress and slip tendency}

Based on Coulomb failure law, the critical condition for rupturing on a pre-existing fault is

$$
\tau=\mu \sigma_{e}=\mu\left(\sigma-P_{f}\right)
$$

where $\tau, \sigma$, and $P_{f}$ are shear stress, normal stress, and pore pressure acting on the fault plane, respectively, and $\mu$ represents the sliding friction of the fault plane. In many cases, the in-situ stress tensor is not well defined, thus change in Coulomb failure stress $(\triangle \mathrm{CFS})$ is useful for fault stability analysis.

$$
\Delta C F S=\Delta \tau-\mu \Delta \sigma_{e}
$$

As seen from above definition, the tendency of fault slip increases with increasing $\triangle C F S$. The slip tendency of the fault is defined as the ratio of the shear stress and normal stress (Morris et al., 1996) and thus equals to the friction coefficient.

$$
T s=\tau / \sigma_{e}
$$

Slip-tendency analysis is a technique that visualises the stress tensor in terms of its associated slip-tendency distribution and the relative likelihood and direction of slip on interfaces at all orientations (Morris et al., 1996). Under a uniform regional stress field, the most optimally oriented fault has the maximum slip tendency, as faults with greater slip tendency values are easier to rupture.

Under the principal stress coordinate system $\left(s_{1}, s_{2}, s_{3}\right)$, the shear and normal stresses on a surface of given direction 
cosines $(l, m, n)$ can be calculated from the three principal stress magnitudes $\left(\sigma_{1}, \sigma_{2}, \sigma_{3}\right)$ as:

$$
\begin{aligned}
\tau^{2} & =\left(\sigma_{1}-\sigma_{2}\right)^{2} l^{2} m^{2}+\left(\sigma_{2}-\sigma_{3}\right)^{2} m^{2} n^{2} \\
& +\left(\sigma_{3}-\sigma_{1}\right)^{2} n^{2} l^{2} \\
\sigma^{2} & =\sigma_{1}^{2} l^{2}+\sigma_{2}^{2} m^{2}+\sigma_{3}^{2} n^{2}
\end{aligned}
$$

Stress inversion based on earthquake mechanism solution can give only the direction of the principal stresses and the stress difference ratio $(R)$, or equivalently, the shape ratio $(\varphi)$

$$
\begin{aligned}
& R=\left(\sigma_{1}-\sigma_{2}\right) /\left(\sigma_{1}-\sigma_{3}\right) \\
& \phi=1-R=\left(\sigma_{2}-\sigma_{3}\right) /\left(\sigma_{1}-\sigma_{3}\right)
\end{aligned}
$$

If $\sigma_{1}-\sigma_{3}$ is not well constrained, we can assume that the frictional sliding envelope is tangential to the $\left(\sigma_{1}, \sigma_{3}\right)$ Mohr circle. Then, the principal stresses are given by (Etchecopar et al., 1981; Gephart and Forsyth, 1984):

$$
\begin{aligned}
& \sigma_{1}=k(1 / \sin (\varphi)+1) / 2 \\
& \sigma_{2}=\sigma_{1}-k R \\
& \sigma_{3}=\sigma_{1}-k
\end{aligned}
$$

where $k$ is an unknown parameter, $\tan \varphi=1 / \tan (2 \theta)=\mu$. Finally, the shear stress and normal stress can be obtained by:

$$
\begin{aligned}
& \tau=k\left[(1-\phi)^{2} l^{2} m^{2}+\phi^{2} m^{2} n^{2}+n^{2} l^{2}\right]^{1 / 2} \\
& \sigma=k\left(\frac{\csc (\varphi)+1}{2}-(1-\phi) m^{2}-n^{2}\right)
\end{aligned}
$$

Therefore, the slip tendency is independent on the unknown parameter $k$, and we can get a slip tendency normalised by the maximum.

\subsection{Coupled THM analysis}

The coupled thermal-hydraulic-mechanic (THM) analysis is carried out by two simulators: TOUGH2 and FLAC3D. TOUGH2 is a multiphase reservoir simulation program developed by the Lawrence Berkeley National Laboratory (LBNL) in the US. FLAC-3D is a commercial software for stress analysis (Itasca, 2000). With couplers (Rutqvist et al., 2002), the 'TOUGH-FLAC' approach has been used in the analysis of deformation accompanied with fluid flow in geothermal studies, and in natural fluid-driven seismicity (Cappa et al., 2009; Todesco et al., 2004). The geometry of the numerical model is shown in Figure 8. According the geological profile shown in Figure 7, four groups of formations are considered. The mechanical and hydraulic properties of each group are listed in Table 1. The far field boundaries are placed at a distance of $10 \mathrm{~km}$ to approximate infinite boundaries. The in-site stress are installed in all zones, and also applied as loads acting on the far-field boundaries. Since we focused on the stress change from gas extraction, precise in-site stress is not required. Hydraulic and mechanic symmetry boundary conditions are imposed on the planes at $x=0$ and $y=0$, thus our model is a $1 / 4$ symmetric model has dimensions of $10 \mathrm{~km}$ in $X$ and $Y$ directions, and $4 \mathrm{~km}$ in $Z$ (depth) direction. This model is divided into grids by varying steps from $50 \mathrm{~m}$ to 2,000 metre according to the distance from the centre point increases. In depth, it is equally split at $200 \mathrm{~m}$ intervals. The total numbers of zones are 9,379. Boundary conditions are rollers everywhere except on the top boundaries. For initial pore-pressure, hydrostatic pore pressure was assumed for upper formations, while the lower two formation are

\begin{tabular}{|c|c|c|c|c|c|}
\hline Property/formation & $J$ & $T_{3} x j$ & $T_{2} l$ & $T_{2} j$ & $T_{l} f$ \\
\hline $\mathrm{Vp}(\mathrm{Pe}=11 \mathrm{MPa}), \mathrm{km} / \mathrm{s}$ & $3.9 \sim 4.0$ & & & & 5.8 \\
\hline Density, $\mathrm{kg} / \mathrm{m}^{3}$ & 2,500 & & & & 2,700 \\
\hline $\mathrm{K} / \mathrm{G}, \mathrm{GPa}$ & $21 / 13$ & & & & $50 / 30$ \\
\hline Frictional coefficient & $0.6 \sim 0.8$ & $\sim 0.7$ & & & \\
\hline Bulk modulus, GPa & 4.85 & 8 & 9 & 9 & 9 \\
\hline Shear modulus, GPa & 3.74 & 4.8 & 5.4 & 5.4 & 5.4 \\
\hline Biot's coefficient & 0.9 & 0.8 & 0.8 & 0.8 & 0.8 \\
\hline Ini. Perm.(k0), $\mathrm{m}^{2}$ & $1 \times 10^{-15}$ & $1 \times 10^{-18}$ & $1 \times 10^{-16}$ & $1 \times 10^{-17}$ & $1 \times 10^{-17}$ \\
\hline Porosity & 0.08 & 0.05 & 0.05 & 0.05 & 0.05 \\
\hline
\end{tabular}
overpressured $(R=1.7)$. For simplicity, we did not include any fault in the numerical model. A reverse stress regime is assumed. The minimum principal stress is vertical and equal to the overburden weight. The $X$ and $Y$ axes are oriented along the maximum and minimum horizontal stress directions, respectively. Amplitude of horizontal stress is determined so that the optimal oriented faults were sub-critically stressed.

Table 1 Major hydraulic and mechanical properties

Note: Data in grey rows are obtained based on laboratory data (Lei et al., 2014). 
Figure 8 Geometry of numerical model used for coupled THM analysis (see online version for colours)

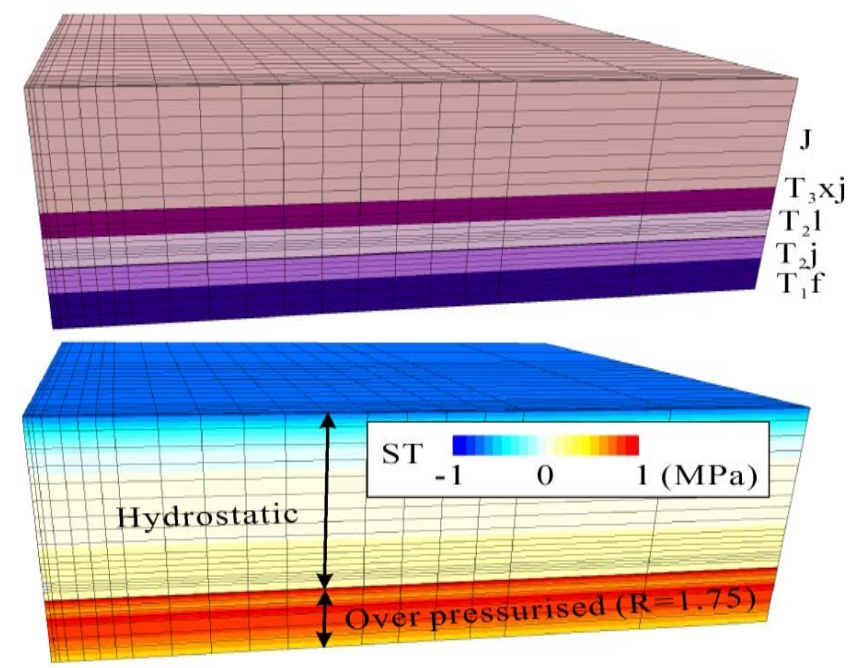

Note: See text for details.

Figure 9 Changes of porepressure $(\mathrm{P})$ and Coulomb failure stress (CFS) at 5 year since the depletion of the upper reservoir (see online version for colours)

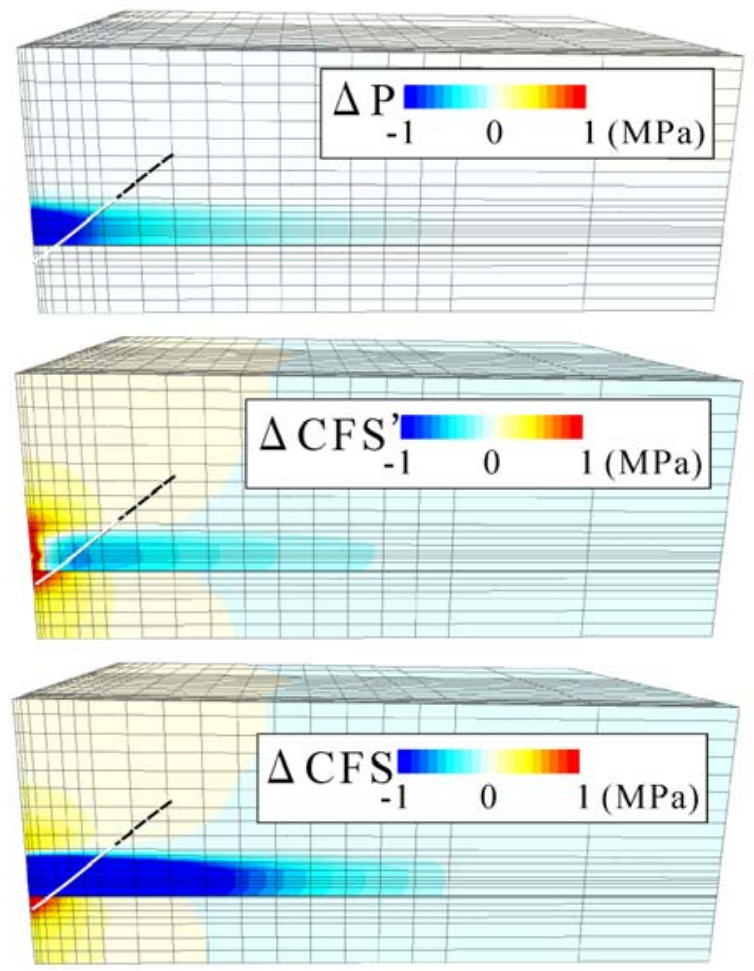

Notes: $\triangle \mathrm{CFS}$ ' indicated the change CFS from rock deformation while $\Delta$ CFS $\left(=\Delta\right.$ CFS $^{\prime}-\mu \Delta \mathrm{P}, \mu$ : friction coefficient) represents the total change of CFS on the presumed fault plane. The estimated ruptured part (while line) of the Tongnan earthquake source fault (black dash line) are also showed.

Due to limitation in production data, we cannot simulate the detailed gas extraction process. Since the upper reservoir was depleted for several years, and depleted reservoirs in this area may keep very low pressure $(<1 \mathrm{MPa})$ for many years, we simply set the initial pore-pressure in the 'well' zone located at the centre $(x=0, y=0)$ and the top of the Leikoupo formation to $1 \mathrm{MPa}$ and simulated stress changes with time. We developed a postprocessor to calculate $\triangle \mathrm{CFS}$ and slip tendency for fault stability analysis. Figure 9 shows results after an elapsed time of five years. The change of Coulomb failure stress was calculated for virtual faults of given dip and rake angles, which are same to the estimated values of moment tensor inversion aforementioned. It is clearly demonstrated that gas production resulted in negative Coulomb failure stress to the source fault except the lower end part penetrated into the lower overpressured formation. Thus, gas extraction has one two-fold role. The major (and upper) part of the fault is prohibited.

\section{Discussion and conclusions}

It has been widely accepted that fluids play an important role in faulting mechanisms and the triggering of earthquakes. A multitude of evidence for the triggering of moderate size earthquakes by deep source fluid has been observed, such as a precursory diffuse carbon dioxide degassing signature (Salazar et al., 2002), seismic tomography results (e.g., Zhao et al., 1996), earthquake migration pattern (e.g., Antonioli, 2005; Miller et al., 2004), focal mechanism solutions (e.g., Terakawa et al., 2013), and remote triggering in geothermal active regions (e.g., Lei et al., 2011).

In general, one earthquake always raises the odds that there will be another by a number of possible mechanisms, including:

\section{1 redistribution of stress on nearby faults \\ 2 viscoelastic recovery \\ 3 pore fluid diffusion.}

The aftershock productivity probably depends on several factors such as lithological properties, fault frictional properties and stress level acting on existing faults. A recent study showed that the productivity of the stacked aftershock sequences in different regions are inversely correlated with the heat flow and existence of deep sedimentary covers (Yang and Ben-Zion, 2009). In a hydrocarbon reservoir, fault reactivation can be caused by several factors (Wiprut and Zoback, 2000). The absence of recorded aftershocks following the Ms5.1 Suining earthquake implies that local conditions did not permit these mechanisms to work. As mentioned, the central Sichuan Basin uplift is characterised as an aseismic region, demonstrating a relatively lower stress level as compared with the shear strength of the existing faults in the region. Thus the factors associated with stress from a moderate size earthquake might be not enough to produce significant seismicity. From this point, we can get some insight from the injection-induced seismicity in nearby gas reservoirs, approximately $150 \mathrm{~km}$ southwest of the Suining earthquake epicentre. Injection of unwanted water in to the Permian formations at a depth of $2,700 \mathrm{~m}$, had induced a greater number of earthquakes including some M5 class earthquakes (Lei et al., 2008, 
2013). By applying the epidemic type aftershock sequence (ETAS) model to the injection-induced earthquake data sets, it is possible to statistically separate the forced seismicity and self-triggered seismicity. Here, the forced seismicity corresponds to seismicity associated with injection factors, while the self-triggered represents Omori's law of aftershocks. In these cases, except some earlier periods of seismicity, the self-triggered seismicity takes only a few tens of percent. Aftershock productivity, including that of some $\mathrm{M} \sim 5$ class earthquakes, is extremely low when compared with normal tectonic earthquakes. Seismicity quickly died out after the shut-down of injection wells. Pore pressure was raised and maintained by injection and is considered as a dominant factor causing swarm seismicity.

With the considerations mentioned, integrated analysis of the focal parameters, the local petroleum geology, and numerical results we propose a possible model for the M5.1 Suining isolated earthquake. This model is similar to the fault-valve model (Sibson, 2007; Sibson et al., 1975) and episodic flow model (Byerlee, 1993), in which episodic gas injection from the underlying and overpressured (note the pressure ratio is as high as 2.13 2.26) Jialingjiang formation plays a role in activating the pre-existing fault and triggering the earthquake (Figure 6). As mentioned in Section 3, studies have shown indications of gas migration from Jialingjiang formation to Leikou formation. Thus, the fault-valve model could work for faults in the Leikou formation which reaches or cuts the mudstone layer at the bottom of Leikou formation. In this model, ruptures nucleate on a small patch, which is locally weakened by overpressure from an overpressured gas pocket and stress from gas extraction in the upper reservoir. The ruptures then propagate out along the fault driven by a much lower, average background stress, with such propagation enabled by strong fault weakening processes activated during dynamic slip. Since the Jialingjiang formation is also characterised by low permeability, the fault could be quickly healed due to reduction of pressure in the injection spot. Unfortunately, we have no data directly demonstrating fault-valve behaviour. A similar model with direct evidence of gas flow $\left(\mathrm{CO}_{2}\right)$ has been observed elsewhere (Salazar et al., 2002).

\section{Acknowledgements}

The present study was partly supported by State Key Laboratory of Earthquake Dynamics, China Earthquake Administration.

\section{References}

Aki, K. (1967) 'Scaling law of seismic spectrum', Journal of Geophysical Research, Vol. 72, No. 4, pp.1217-1231.

Antonioli, A. (2005) 'Fluid flow and seismicity pattern: evidence from the 1997 Umbria-Marche (central Italy) seismic sequence', Geophysical Research Letters, Vol. 32, L10311, doi:10.1029/2004GL022256.
Bai, G. (1992) 'Relation between stylolite and reservoir in Moxi gas field', Oil and gas Geology, in Chinese, Vol. 13, No. 4, pp.418-422.

Bakun, W.H. and McEvilly, T.V. (1981) 'P-wave spectra for ML 5 foreshocks, aftershocks, and isolated earthquakes near Parkfield, California', Bulletin of the Seismological Society of America, Vol. 71, No. 2, pp.423-436.

Boddington, T., Parkin, C.J. and Gubbins, D. (2004) 'Isolated deep earthquakes beneath the North Island of New Zealand', Geophysical Journal International, Vol. 158, No. 3, pp.972-982.

Bowman, J.R., Collins, J.A., Bostock, M.G., Grant, J. and Bowman, C.C. (1990) 'The ayers rock, australia, earthquake of 28 may 1989: a temporally isolated MB 5.8 intraplate event', Bulletin of the Seismological Society of America, Vol. 80, No. 2, pp.313-324.

Byerlee, J.D. (1993) 'Model for episodic flow of high-pressure water in fault zones before earthquakes', Geology, Vol. 21, No. 4, pp.303-306.

Cappa, F., Rutqvist, J. and Yamamoto, K. (2009) 'Modeling crustal deformation and rupture processes related to upwelling of deep $\mathrm{CO}_{2}$-rich fluids during the 1965-1967 Matsushiro earthquake swarm in Japan', Journal of Geophysical Research, Vol. 114, B10304, doi:10.1029/2009JB006398.

Dai, M., Huang, Q., Wang, H. and Hu, L. (1998) 'Study on transverse migration of natural gas - example of Moxi gas reservoir of Sichuan basin', Natural Gas Geoscience, in Chinese, Vol. 9, No. 2, pp.7-11.

Eshelby, J.D. (1957) 'The determination of the elastic field of an ellipsoidal inclusion, and related problems', Proceedings of the Royal Society of London A: Mathematical, Physical and Engineering Sciences, The Royal Society, pp.376-396.

Etchecopar, A., Vasseur, G. and Daignieres, M. (1981) 'An inverse problem in microtectonics for the determination of stress tensors from fault striation analysis', Journal of Structural Geology, Vol. 3, No. 1, pp.51-65.

Gephart, J.W. and Forsyth, D.W. (1984) 'An improved method for determining the regional stress tensor using earthquake focal mechanism data: application to the San Fernando earthquake sequence', Journal of Geophysical Research: Solid Earth (1978-2012), Vol. 89, No. B11, pp.9305-9320.

He, Y., Zhou, R., Li, Y. and Wang, Z. (2010) 'Overview for the Suining-Tongnan M5. 0 earthquake on January 31, 2010 in the border area between Sichuan and Chongqing, Western China', Earthquake Research in China, Vol. 26, No. 2, pp.235-241.

Itasca, F. (2000) Fast Lagrangian Analysis of Continua, Itasca Consulting Group Inc., Minneapolis.

Jia, G., Yang, J., Zhao, Y. et al. (2005) 'Research and application of Radon exploration: efficiency of indication of oil and gaswater boundary by radon anomaly in Moxi gas pool', Mineral Resource and Geology, Vol. 19, No. 4, pp.403-413.

Kanamori, H. (1977) 'The energy release in great earthquakes', Journal of Geophysical Research, Vol. 82, No. 20, pp.2981-2987.

Lei, X., Ma, S., Chen, W., Pang, C., Zeng, J. and Jiang, B. (2013) 'A detailed view of the injection-induced seismicity in a natural gas reservoir in Zigong, Southwestern Sichuan Basin, China', Journal of Geophysical Research: Solid Earth, Vol. 118, doi: 10.1002/jgrb.50310. 
Lei, X., Xie, C. and Fu, B. (2011) 'Remotely triggered seismicity in Yunnan, southwestern China, following the 2004Mw9.3 Sumatra earthquake', Journal of Geophysical Research, Vol. 116, B08303, doi:10.1029/2011JB008245.

Lei, X., Yu, G., Ma, S., Wen, X. and Wang, Q. (2008) 'Earthquakes induced by water injection at $-3 \mathrm{~km}$ depth within the Rongchang gas field, Chongqing, China', Journal of Geophysical Research, Vol. 113, B10310, doi:10.1029/2008JB005604.

Lei, X-L., Li, X-Y., Li, Q., Ma, S-L., Fu, B-H. and Cui, Y-X. (2014) 'Role of immature faults in injection-induced seismicity in oil/gas reservoirs - a case study of the Sichuan Basin, China', Geology and Seismology, in Chinese, Vol. 36, No. 3, pp.625-643.

Li, W. (2012) 'Indication of natural gas migration and accumulation by three-dimensional fluorescence characteristics of gas-field waters: a case study of the Permian-Triassic in the central-western Sichuan Basin', Petroleum Exploration and Development, Vol. 39, No. 2, pp.202-211.

Lundgren, P. and Giardini, D. (1994) 'Isolated deep earthquakes and the fate of subduction in the mantle', Journal of Geophysical Research, Vol. 99, No. B8, pp.15833-15842.

Luo, Y., Ni, S., Zeng, X., Xie, J., Chen, Y. and Long, F. (2011) 'The M5.0 Suining-Tongnan (China) earthquake of 31 January 2010: a destructive earthquake occurring in sedimentary cover', Chinese Science Bulletin, Vol. 56, No. 6, pp.521-525.

Madariaga, R. (1976) 'Dynamics of an expanding circular fault', Bulletin of the Seismological Society of America, Vol. 66, No. 3, pp.639-666.

Michael-Leiba, M., Love, D., McCue, K. and Gibson, G. (1994) 'The Uluru (Ayers Rock), Australia, earthquake of 28 May 1989', Bulletin of the Seismological Society of America, Vol. 84, No. 1, pp.209-214.

Miller, S.A., Collettini, C., Chiaraluce, L., Cocco, M., Barchi, M. and Kaus, B.J. (2004) 'Aftershocks driven by a high-pressure $\mathrm{CO}_{2}$ source at depth', Nature, Vol. 427, pp.724-727 (19 February 2004).

Morris, A., Ferrill, D.A. and Henderson, D.B. (1996) 'Slip-tendency analysis and fault reactivation', Geology, Vol. 24, No. 3, pp.275-278.

Nicholson, C., Roeloffs, E. and Wesson, R. (1988) 'The northeastern Ohio earthquake of 31 January 1986: was it induced?', Bulletin of the Seismological Society of America, Vol. 78, No. 1, pp.188-217.

Ottemöller, L. and Havskov, J. (2003) 'Moment magnitude determination for local and regional earthquakes based on source spectra', Bulletin of the Seismological Society of America, Vol. 93, No. 1, pp.203-214.

Rutqvist, J., Wu, Y-S., Tsang, C-F. and Bodvarsson, G. (2002) 'A modeling approach for analysis of coupled multiphase fluid flow, heat transfer, and deformation in fractured porous rock', International Journal of Rock Mechanics and Mining Sciences, Vol. 39, No. 4, pp.429-442.

Salazar, J.M.L., Pérez, N.M., Hernández, P.A., Soriano, T., Barahona, F., Olmos, R., Cartagena, R., López, D.L., Lima, R.N., Melián, G., Galindo, I., Padrón, E., Sumino, H. and Notsu, K. (2002) 'Precursory diffuse carbon dioxide degassing signature related to a 5.1 magnitude earthquake in El Salvador, Central America', Earth and Planetary Science Letters, Vol. 205, Nos. 1-2, pp.81-89.
Schwartz, S.Y. and Christensen, D.H. (1988) 'The 12 July 1986 St. Marys, Ohio earthquake and recent seismicity in the Anna, Ohio seismogenic zone', Seismological Research Letters, Vol. 59, No. 2, pp.57-62.

Segall, P. (1992) 'Induced stresses due to fluid extraction from axisymmetric reservoirs', Pure and Applied Geophysics, Vol. 139, Nos. 3-4, pp.535-560.

Segall, P., Grasso, J.R. and Mossop, A. (1994) 'Poroelastic stressing and induced seismicity near the Lacq gas field, Southwestern France', Journal of Geophysical Research: Solid Earth (1978-2012), Vol. 99, No. B8, pp.15423-15438.

Sibson, R.H. (2007) 'An episode of fault-valve behaviour during compressional inversion? - The 2004 MJ6.8 Mid-Niigata Prefecture, Japan, earthquake sequence', Earth and Planetary Science Letters, Vol. 257, Nos. 1-2, pp.188-199.

Sibson, R.H., Moore, J.M.M. and Rankin, A. (1975) 'Seismic pumping - a hydrothermal fluid transport mechanism', Journal of the Geological Society, Vol. 131, No. 6, pp.653-659.

Stauder, W. and Pitt, A.M. (1970) 'Note on an aftershock study, south central Illinois earthquake of November 9, 1968', Bulletin of the Seismological Society of America, Vol. 60, No. 3, pp.983-986.

Terakawa, T., Hashimoto, C. and Matsu'ura, M. (2013) 'Changes in seismic activity following the 2011 Tohoku-oki earthquake: effects of pore fluid pressure', Earth and Planetary Science Letters, Vol. 365, No. 1, pp.17-24.

Todesco, M., Rutqvist, J., Chiodini, G., Pruess, K. and Oldenburg, C.M. (2004) 'Modeling of recent volcanic episodes at Phlegrean Fields (Italy): geochemical variations and ground deformation', Geothermics, Vol. 33, No. 4, pp.531-547.

Wang, S., Dai, H., Wang, Y. and Lin, F. (1998) 'Source and migration of the highly-matured natural gas in Moxi gas field, Sichuan basin, China', Petroleum Explorationist, in Chinese, Vol. 3, No. 2, pp.5-8.

Wang, X., Ma, S., Guo, Z., Lei, X., Xia, Y., Guo, X., Yu, G., Gou, X. and Jiang, X. (2013) 'S-wave velocity of the crust in three Gorge reservoir and the adjacent region inverted fro siemic ambient noise tomography', Chinese J. Geophys., in Chinese, Vol. 56, No. 12, pp.4113-4112.

Wiprut, D. and Zoback, M.D. (2000) 'Fault reactivation and fluid flow along a previously dormant normal fault in the northern North Sea', Geology, Vol. 28, No. 7, pp.595-598.

Xu, C., Li, J., Yang, J. and Gong, C. (2006) 'Triassic T3j2 reservoir of Moxi Gas Field in Sichuan Basin', Marine Petroleum Geology, in Chinese, Vol. 11, No. 4, pp.54-61.

Yang, W. and Ben-Zion, Y. (2009) 'Observational analysis of correlations between aftershock productivities and regional conditions in the context of a damage rheology model', Geophysical Journal International, Vol. 177, No. 2, pp.481-490.

Zhang, Y., Long, F. and Su, J. (2011) 'Prelinminary analysis of the waveform feature and the causes for the Ms5.0 Suining Earthquake on Jan 31, 2010', Journal of Seismological Research, in Chinese, Vol. 34, No. 2, pp.119-125.

Zhao, D., Kanamori, H., Negishi, H. and Wiens, D. (1996) 'Tomography of the source area of the 1995 Kobe Earthquake: evidence for fluids at the hypocenter?', Science, Vol. 274, pp.1891-1894 (13 December 1996).

Zhu, L. and Ben-Zion, Y. (2013) 'Parameterization of general seismic potency and moment tensors for source inversion of seismic waveform data', Geophysical Journal International, Vol. 194, No. 2, pp.839-843. 